ISO 9000 Internalization and Organizational Commitment Implications for Process Improvement and Operational Performance

\author{
Cigdem Ataseven \\ Cleveland State University, c.ataseven@csuohio.edu \\ Daniel I. Prajogo \\ Anand Nair
}

Follow this and additional works at: https://engagedscholarship.csuohio.edu/bus_facpub

Part of the Technology and Innovation Commons

How does access to this work benefit you? Let us know!

\title{
Publisher's Statement
}

This is an Author's Accepted Manuscript of an article published in IEEE Transactions on Engineering Management, 2014, DOI: 10.1109/TEM.2013.2285344, available online: http://ieeexplore.ieee.org.

\section{Original Published Citation}

Ataseven, C., Prajogo, D. I., Nair, A. (2014). ISO 9000 Internalization and Organizational Commitment Implications for Process Improvement and Operational Performance. IEEE Transactions on Engineering Management, 6(1), pp. 5-17.

This Article is brought to you for free and open access by the Monte Ahuja College of Business at EngagedScholarship@CSU. It has been accepted for inclusion in Business Faculty Publications by an authorized administrator of EngagedScholarship@CSU. For more information, please contact library.es@csuohio.edu. 


\title{
ISO 9000 Internalization and Organizational Commitment-Implications for Process Improvement and Operational Performance
}

\author{
Cigdem Ataseven, Daniel I. Prajogo, and Anand Nair
}

\begin{abstract}
This study presents an investigation of the relationship between internalization of ISO 9000 practices and the development of intellectual capital within organizations. We posit that intellectual capital, which comprises of human capital, organizational capital, and social capital, leads to improved processes in an organization. Process improvement, in turn, results in superior operational performance. Using a sample of 321 ISO 9001 certified organizations, the hypotliesized relationships are tested by means of the structural equation modeling technique. The results of this study lend strong support for the hypotheses and show that performance benefits from the internalization of $15 O 9000$ standards oc cur mainly through the development of human and organizational capital, and the consequent improvement in business processes. This study discusses theoretical and managerial inplications, and presents directions for future research.
\end{abstract}

Index Terms-ISO 9000, intellectual capital, internalization, knowledge management, performance, process improvement, quality management.

\section{INTRODUCTION}

O VER the last two decades, there has been a steady increase in the number of countries that have adopted ISO 9000 as their national quality standard. Many organizations within these countries have gone through the certification process and have executed the required procedures on varying levels [1]. Corresponding to this movement, research on various themes related to ISO 9000 has proliferated. Most of the earlier studies on ISO 9000 are descriptive, where the researchers sought to investigate the main reasons and benefits of getting the ISO 9000 certification [2], [3]. Other studies have focused on the link between ISO 9000 implementation with process improvement and performance [4]-[7].

While these studies help us understand the drivers and the success factors which determine the outcomes of ISO 9000 adoption, the mechanism through which ISO 9000 adoption links to the performance benefits is less clear. Specifically, it is still relatively ambiguous how ISO 9000 practices are translated into firm's capabilities (or capital), and how this accumulated capital results in superior performance. The hidden mechanisms that translate the internalization of ISO 9000 standards to performance outcomes require further research examination. In this study, we aim to shed light on those mechanisms by explicitly considering the distinction between internalization of the practices emphasized by ISO 9000 standards and implementation of procedures that lead to ISO 9000 certification. Specifically, we theorize about the distinct nature of internalization of ISO 9000 standard, and consider the role it plays in organizational transformation by building intellectual capital. To our knowledge, this is the first study to look at intellectual capital building as a means to achieve process improvement and enhanced operational performance. We took capabilities as a point of reference, since the expected outcome of ISO 9000 certified firms is that they will produce higher quality products or services, which meet or exceed customer's' needs and expectations. Given our notion that ISO 9000 internalization does contribute to quality improvement, we aim to investigate what kind of resources or capabilities can explain the variance of performance among the ISO 9000 adopters.

In this study, we focus on intellectual capital, which is inherently built within the organizations via the internalization of ISO 9000 standards. We argue that internalization of ISO 9000 is not simply conformance or compliance to requirements of a standard of practice, but is also a process of building capital, which would provide competitive advantage to organizations. We posit that knowledge management related practices that result from internalization of ISO 9000 standards elevate to higher order understandings in the firm and end up shaping the ways the organization operates. The most obvious benefit is in terms of improved operational performance. This study brings attention to important supplemental benefits of internalization of ISO 9000 on intellectual capital building, and considers intellectual capital as a source of sustainable competitive advantage. Specifically, we theorize that human, organizational, and social capital form the basis for intellectual capital, which helps form a common understanding and collective effort to reach the desired performance levels. So far, few studies on ISO 9000 have addressed the relation between the quality system standard and knowledge accumulation and management within the firms, e.g., [10]. [11]. We believe that understanding these issues is important, since quality assurance based on ISO 9000 is 
dependent on a dynamic process of acquisition, accumulation, and maintenance of knowledge.

The proper implementation of ISO 9000 improves the design and development of systems in the organization including human and knowledge related routines. Our framework linking ISO 9000 standards with human resource outcomes follows the findings in the prior literature. To build our theoretical arguments, we resort to the intellectual capital theory [12] and the resource-based view [13]. The key premise that we investigate is whether internalization of ISO 9000 standards leads to the development of human capital (people), organizational capital (documentation and information storage), and social capital (networks of interrelationships). This study extends the research stream by considering the ISO 9000 standards as embedded knowledge and employee competencies in the workplace. The internalization of both tacit and explicit knowledge results in the adoption of the underlying practices emphasized by ISO 9000 standards by managers and decision makers. Therefore, execution of and dedication to these standards actually make a difference by building knowledge-related capabilities in the firm. The efforts to internalize the main principles then become a strategic approach to enjoy the benefits gained as a result of these quality standards. It means that the extent of actual use of ISO 9000 standards and their internalization would be a more important managerial concern than the mere fact of having the certification in place.

\section{TheOretiCAL Foundation AND HYPOTHESES DEVELOPMENT}

\section{A. Internalization of ISO 9000 Standards}

In this study, we focus on internalization of ISO 9000 standards to build our conceptual framework. Internalization of ISO 9000 standards, as against mere implementation, translates into the adoption of the underlying practices of ISO 9000 by managers and decision makers in their daily use [4], [14], [15]. Recently, studies in quality management area emphasize the need for internalization of ISO standards to achieve performance benefits [14], [16]-[18]. Internalization of ISO 9000 standards ensures that it is not implemented as a latest fad, and is not just a certification, but instead, is aimed at fostering strategic quality management to enable streamlined operations and continuous process improvement. This is achieved by first establishing a set of policies and standard procedures, which describe how processes in the firm will be conducted and maintained consistently. However, apart from documenting processes, internalization of ISO 9000 also requires firms to communicate the written procedures to employees and empower them to adhere to the procedures. Finally, firms need to perform internal audits to ensure the compliance of the firm's procedures against ISO 9000 requirements [22].

If the key to success is internalization, rather than simply implementation, one may ask how the transition from implementation to internalization occurs when we consider ISO 9000. ISO 9000 standards contribute to the knowledge codification process in two ways [10]. First of all, they act as a tool that helps a firm to combine or formalize a form of knowledge, called the codified knowledge, within the firm, and to externalize or codify another form of knowledge, called the tacit knowledge that is embedded in people, and to socialize people or share experiences via discussions about the process. Second, the documentation, or alternatively called standardization, has to be used again by the employees to be productive and contribute to organizational knowledge accumulation. Thus, socialization and standardization are important aspects of internalization of ISO 9000 .

The impact of ISO 9000 standards on the knowledge structure of the firm is undeniable. Tacit knowledge, which is related to action, commitment, and involvement regarding a particular context, is kept in human mind. Although not formalized, tacit knowledge shapes perspectives and perceptions of the human subjects. On the other hand, explicit (alternatively called codified) knowledge is transferred via formal and systematic languages [19]. Management of knowledge basically reflects two modes of conversion, where tacit and explicit knowledge interact with each other in networks of relationships.

The intellectual capital theory and resource-based view are the main theoretical frameworks used to shed light on the interplay between internalization of ISO 9000 practices and the development of intellectual capital in this study. Subramaniam and Yound articulate intellectual capital in their study on innovative capability building [12]. Intellectual capital basically comprises of three aspects: human, organizational, and social capital. They define human capital as "the knowledge, skills, and abilities residing with and utilized by individuals," organizational capital as "the institutionalized knowledge and codified experience residing within and utilized through databases, patents, manuals, structures, systems, and processes" and social capital as "knowledge embedded within, available through, and utilized by interactions among individuals and their networks of interrelationships" [12]. This study examines the impact of internalization of ISO 9000 standards on the development of intellectual capital, and the resulting performance implications.

The building blocks of human capital are creative, bright, skilled employees, with expertise in their roles and functions, who constitute the major source for new ideas and knowledge in an organization [21]. As such, human capital requires the hiring, training, and retaining of employees. However, since human capital is embedded in individual expertise, it may not necessarily stay within organizations due to the mobility of employees. As a result, human capital can come into and go from organizations. On the other hand, the main tenets of organizational capital include reliance on manuals, databases, patents, and licenses to codify and preserve knowledge, along with establishment of structures, processes, and routines that encourage repeated use of this knowledge [20]. As such, organizational capital, which takes form in institutionalized knowledge stays within organizations and does not change very easily. This is because organizational capital is related to codification and preservation of knowledge through structured and repetitive activities. The codification is manifested in the forms of manuals, clatabases, and patents that organizations use to accumulate and retain knowledge. At the same time, organizational capital is also concerned with formal procedures and rules for retrieving, sharing, and 
utilizing knowledge. In essence, organizational capital aims to institutionalize knowledge within an organization by means of preserving knowledge and by incorporating mechanisms to use it recurrently. Social capital emerges from norms of collaboration, interaction, and sharing of ideas. This form of intellectual capital does not follow predetermined rules for knowledge transmission; instead, it requires structures that facilitate the interactions in networks. Although the dimensions of intellectual capital may sound different, they transform into and are transferred via each other, and ultimately unfold the organizational knowledge [12].

\section{B. Linking Internalization of 1509000 Standards With Human Capital}

As indicated before, human capital is "the knowledge, skills, and abilities residing with and utilized by individuals" [12]. The link between internalization of ISO 9000 standards and hum man capital, although intuitive, has been rarely discussed in the literature. The importance of employee involvement to the organization is very critical. This also holds true when one considers the implementation of various organization-wide programs and procedures. The success of these programs is dependent on how employees perceive, accept, and communicate the new practices in the work place. Several studies focusing on quality management have emphasized the contribution from the employees for superior performance [26], [27]. Therefore, managers need to fully convince employees about the virtues of ISO 9000 -based quality system to get their support [28]. They also need to ensure that the employees have the appropriate skills to adopt modern quality-related practices [29]. If the required skills of the employees are not readily available, appropriate training efforts should be undertaken [4]. The internalization of ISO 9000 practices involves training and assurance of compliance with well-documented processes to make ISO 9000 implementation effective and potentially cistinctive.

Organizational knowledge flows through people as well as through technological means. Further, the knowledge transfer is facilitated by networks that can manifest in terms of linkages among organizational members (social networks), in the form of organizational routines (task networks) and as technological networks [30]. Embedded knowledge in the organization's reservoirs transferred via networks becomes a valuable resource and a basis of competitive advantage [30]. Internalizing ISO 9000 quality standards helps in developing intellectual capital that forms the basis for the knowledge management of the organization, and enables to instill changes in the knowledge structure. This, in turn, is related to the resource-based view of the firm, which argues that a firm gains sustained competitive advantage when it possesses resources that are valuable, rare, inimitable, and nonsubstitutable [8], [13], [31]. Firm resources include at assets, capabilities, processes, attributes, information, and knowledge that are embodied in the firm [13]. The resources of the firm are mainly classified into physical, human, and organizational assets [13]. With ISO 9000 internalization, the intangible resources of skilled manpower and embedded knowledge get transformed into inimitable assets. At that point
ISO 9000 goes beyond certification and acts as a source of competitive advantage as a result of enhanced employee skills and competencies, higher levels of motivation, and improved use of knowledge and information.

As mentioned previously, mere ISO 9000 certification does not assure success. Over an extended period of time, the assimilation of the main tenets of the program, such as intensive documentation requirements, use of quality tools, collaboration, and training, elevates the scope and impact of ISO 9000 implementation beyond finding a solution to a quality-related issue. We argue that this is when ISO 9000 is internalized and when it changes the way people contribute to the organization by their changed mindsets and skill levels. Based on this reasoning, we hypothesize:

H1: Mernalization of ISO 9000 standards is positively associated with human capital.

\section{Linking Internalization of ISO 9000 Standards With Organizational Capital}

As introduced previously, organizational capital is "the institutionalized knowledge and codiffed experience residing within and utilized through databases, patents, manuals, structures, systems, and processes" [12]. Knowledge, especially knowledge codification and knowledge accumulation of processes closely relates to the ISO 9000 implementation because the implementation process requires strict documentation of products and processes within the firm [32]. Organizational capital emerges as ISO 9000 is implemented and internalized within the firm because of the profound documentation requirements that the quality management system hinges on for standardization purposes. In a sense, internalization of ISO 9000 influences the foundation of the firm by means of information flow and knowledge dissemination. It impacts how the information is documented and stored throughout the organization, and shapes the knowledge structure of the firm. Similar to human capital, organizational capital acts as an inimitable and intangible resource, which can be a potential performance driver for the firm [13].

In general, the documentation process has two goals. The first one is that the knowledge, which is tacit and embedded in the human brain, can be codified, and preserved through documentation of processes. People may join and leave organizations. The preservation of knowledge assures that the knowledge will remain within organizations. Second, documentation of processes is a mechanism of institutionalizing organizational knowledge which results in reduced variability in the production operations. Standardization of processes is achieved via documentation of repetitive actions within the firm. This is important in the process of continuous improvement and consistency of the new and improved operations. There are several studies that consider ISO 9000 as an information sharing tool to improve quality and performance [11]. Therefore, implementation of ISO 9000 programs can in fact be thought of as a form of dissemination of knowledge related to quality management and can train the employees regarding the ways of knowledge transfer at large. ISO 9000 standards are considered to be a codebook 
that is similar to a repository of the existing practices gathered via observations [10].

Thus, the way ISO 9000 series work is through formalization of codified knowledge and conversion from tacit to codified knowledge. The firm achieves this ability to document, convert, and disseminate knowledge by the practices that take place during the implementation and internalization of ISO 9000 programs. Since the extent and ability of each firm to internalize ISO 9000 practices may change, the degree to which organizational capital is accumulated in the firm as a result of documentation conventions also changes. Therefore, we hypothesize:

H2: Intemalization of ISO 9000 standards is positively associated with organizational capital.

\section{Linking Internalization of ISO 9000 Standards With Social Capital}

From knowledge management perspective, tacit and explicit knowledge work synergistically and they can expand over time via the process of mutual interactions [19]. This requires communication among forms of knowledge in various networks. It means that enhanced employee capabilities and improved knowledge dissemination processes in the organization can build shared systems, interpretations, and understandings among organizational entities that shape up the higher order culture in the organization. The interactions between tacit and explicit knowledge have been emphasized in the extant operations management literature [33]. Groups and interactions constitute important elements in dissemination of knowledge in organizations [19]. Moreover, teamwork and collaboration inproves the way the institutionalized knowledge is used, updated, and reinforced.

The network concept is critical especially in the knowledge dissemination process because employees interact with each other as well as with the tasks and knowledge reservoirs of the organization to settle on a common understanding of the goals. Therefore, the capabilities of the human actors along with knowledge dissemination tools set the ground for networking of information. Collective understanding of the shared knowledge and congruence of goals directed by the ISO 9000 standards is achieved via employees that are social actors and their information exchange. In this case, the dimensions of social capital as well as information exclange are potentially at work [34]-[36]. Institutionalized norms and conventions establish congruence and alignment regarding how the task is done and what the outcome should be. Shared experiences within networks enhance common perspectives and form a common base for understanding [19].

In sum, ISO implementations include individual and collective knowledge conversions that happen among the parties involved in business relationships [10]. The mutual understanding between the focal organization and its partners is necessitated by the quality management standard in place. Perceived quality is one of the many important dimensions of quality. Since the customer determines the perception, the need to understand customers is paramount [72]. Moreover, in order to deliver good quality, the supptiers of the organization have to understand the requirements and specifications of the focal firm. There is a great degree of information exchange and knowledge buildup in the process to make this collaboration happen. Overall, the social know-how embodied in the organization is generated by the emphasis placed on information exchange and clear understanding of the goals, driven by the internalization of ISO 9000 standards. In light of this theoretical background, we hypothesize:

H3: Intemalization of 1 SO 9000 standards is positively associated with social capital.

\section{E. Process Improvenent}

Process management is at the heart of ISO 9000 standards, and managing the processes is the key application of the quality system [22]. One of the main objectives of ISO 9000 standards is to provide guidance for firms to identify, design, establish, and continually improve key processes within their operating systems, which have capabilities in obtaining results in terms of quality products or services in an effective and efficient way. By focusing on their key processes, firms will be able to understand the stages and the sequence of their activities as well as their interactions in creating value in the products or services delivered to customers.

Participation by the employees as well as education and training of the workforce play a critical role in the pursuit of process improvement since they foster smooth implementation of ISO 9000 standards [17]. ISO 9000 certified firms claim an increased employee involvement and commitment to quality management with the certification process [37]. This is because human assets of the firm are perhaps the most important constituents to ensure consistent quality, and improvement in products and processes. The literature on quality management has shown the significant role of the capabilities of people in realizing continuous improvement in the organizations [38]. In this regard, the ability of people in applying the knowledge in performing their tasks acts as the strategic asset for organizations [39]. Studies have shown that combining personal knowledge and organizational systems that allow employees to independently come up with solutions to organizational problems play an important role in enhancing the performance of leading organizations [40]. The key issue here is to build a connection between the management system (in this case quality management system) of the organization's work processes and the ability to use the employees' knowledge to produce a quick solution to the customers' demands and requirements [41]. Therefore, the work processes can be improved when employees have confidence as a result of having expertise, personal knowledge, and abilities, and this brings positive changes to the effectiveness and efficiency of processes in the organization [42]. These positive changes mostly take place because process improvement will always entail imovative elements (at various degrees) facilitated by skilled manpower within the organization [12]. More importantly, the ability for improving processes is based on the ability of employees in analyzing the processes as "process owners" and coming up with the appropriate solutions [43].

Within ISO 9001:2000 context, since people use knowledge and quality information to solve problems, they essentially 
generate new knowledge that will trigger improvement opportunities [44]. As a result, instead of merely solving current problems, organizations can create improvement opportunities by identifying potential problems that can be solved by developing and applying new knowledge [45]. Thus, well-trained and competent employees enable the firm to adhere to proper execution of processes and contribute to the existing processes by finding novel and better ways to structure these processes [12]. Accordingly, we hypothesize:

\section{H4: Hanan capital is positively associated with process improve-} ment.

Knowledge itself has been considered as one of the strategic assets of an organization [46]. In the context of ISO 9000 , documenting procedures serves the purpose of codifying knowledge from tacit knowledge into explicit knowledge [10]. It is suggested that documentation in ISO 9000 has several benefits, such as lending consistency in the processes, enabling control of the processes, providing guidance for training, and most importantly, facilitating continuous improvement [47]. This is because documentation provides continual updates and information retrieval (internal and external) associated with organizational processes as well as a guide or codebook that depicts the procedures and sets the standards.

As Teece and Pisano note, deep process understanding is the key to process improvement [48]. Documentation is therefore critical because the effectiveness of the work processes in the organization is based on the ability to integrate the updates in real time and to synchronize the ability and knowledge of employees into a system-wide solution for the organizations [42]. The flow of information, formal documentation of the quality issues, and communication achieved through quality personnel's liaison role are generally mentioned to be the enablers of successful process management [17]. Thus, organizational capital has a great influence on operational processes with its properties of creation, transfer, sharing, and embedding of knowledge. Accordingly, we hypothesize:

\section{H5: Organizational capisal is positively associated with process improtement.}

ISO 9000 documentation functions as a communication tool, since it provides information access to all people, and it facilitates information sharing within and between the organizations. This enables people within an organization to gain the knowledge needed to enhance quality and performance of processes [49]. Especially, when the focal organization is in a collaborating relationship with its suppliers and customers, the relational structure plays a vital role to enhance the communication to ensure the quality outcomes. The organization's internalized knowledge improves the quality of collaboration and relationships between the individuals, and creates an interactive environment among the parties involved [12]. The ISO 9000 structure guides the knowledge sharing among the members of the organization and its partners. The problem solving approaches and the process orientation related to ISO 9000 internalization lead to integration and alignment of processes as a result of shared knowledge and common understanding between the parties. Since social capital depends on the ability to share and leverage knowledge among the business partners through the close relationships internally among the employees, and externally with suppliers and customers, it spans the business from top to bottom, and enables not only problem solving for $\mathrm{mi}$ nor process problems but also major process reengineering [7!]. Accordingly, we hypothesize:

H6: Social capiral is positively associated with process inprowement.

\section{F. Operational Perfomance}

So far, we have discussed how socialization and standardization aspects of ISO 9000 provide the basis for intellectual capital building and how the resulting firm assets lead to improved processes. We basically propose that firm specific intel.. lectual capital can be a distinguishing factor when we consider the relationship between ISO 9000 and process improvement. That is how standardized procedures, knowledge, routines, and resources turn into idiosyncratic firm assets, or capital, that go beyond generic process management practices and form firm capabilities that are inimitable, nonsubstitutable, valuable, and rare. Achieving distinctive capabilities that lead to sustained competitive advantage via this type of resource is at the heart of resource-based view [13]. In this section, we want to focus on the operational performance results of improved processes.

One of the major changes in the ISO 9000:2001 compared to the previous version (i.e., 1994) is that the recent version of ISO standards is more process focused in the sense that it puts a greater extent of attention on the application of a system of processes within an organization. In addition, the standards emphasize the identification and interactions of these processes, and best practices for managing the processes. This is because processes are where the value is created, and organizations gain advantages by value-added activities. Processes are a sequence of value adding stages designed to deliver a product and service to external and internal customers [50]. In fact, processes amalgam procedures, people, and technologies as a complex system, which produces organizational routines that are repeatedly executed. Such a systemic routine emerges into a bundle of resources and practices which are difficult to imitate [51], [52]. Therefore, while process improvement appears to be generic as organizations can easily access information on the subject matter, the implementation of improvement itself will lead to unique capabilities. This is because process improvement will be applied to organization-specific context by streamlining the processes and the links between processes across the organization. Therefore, organizations that are able to manage and improve processes, which bring effectiveness of their quality system build specific, unique, and inimitable capabilities, which create values for customers and competitive advantage for the organizations [13], [31].

Since process management is aimed directly at organizationspecific processes and capabilities, and in particular, at streamlining and the snooth flow of linked processes across an organization, improved processes affect the potential for firms' capabilities to lead to competitive advantage in terms of operational performance. Expectations from process management practices 
are improved quality and efficiency, increased revenue, reduced costs, and ultimately, higher profits. While several studies have shown the positive effect of ISO 9000 standards on business performance [23], [32], we posit that such effect is a result of the operational performance derived by adopting ISO 9000 practices. Therefore, we hypothesize:

H7: Process improvement is positively assockated with operational performance.

Bringing all of the hypotheses together, we present our overall conceptual model as in Fig. I.

\section{RESEARCH DESIGN}

\section{A. Sample and Procedures}

The sample of this study was drawn from the database of Joint Accreditation System - Australia and New Zealand (JAS-ANZ), an organization, which registers all firms that are certified in international standards in Australia and New Zealand. 1300 Australian firms were randomly selected out of a total of 10015 firms in the database. The targeted respondents were managers, or personnel who had knowledge on the internalization or maintenance of the firms' quality system, and preferably the firm's management representative of the quality system. The JAS-ANZ database provided the names of these targeted respondents, most of whom are the management representatives of the quality system in the organizations. We provided no specific incentives for the respondents to minimize potential bias, except providing an executive report for respondents who requested it. In total, we received 321 usable responses for the purpose of this study, accounting for $24.7 \%$ response rate.

\section{B. Nonresponse Bias}

We tested nonresponse bias by checking the responses between early respondents and late respondents [55]. The Chisquare test in terms of organizational size and the year of certification did not indicate significant differences between the two subgroups, suggesting that nonresponse bias was not a problem in this dataset. In addition, we also made random follow-up phone calls to identify the firms that decided not to participate in the survey. Out of 50 phone calls made, 30 nonresponding firms were identified, and none of them stated particular reasons, which constituted systematic reasons for not participating in the study. Commonly stated reasons during this phone follow up were "not interested" and "too busy." Therefore, we are confident that the potential nonresponse bias in our dataset is minimal.

\section{Profile of the Respondents}

The sample encompasses firms from both manufacturing and nonmanufacturing sectors with nearly equal representation. The list of industry sectors captured in the sample is presented in Table I. In terms of organizational size, $52 \%$ of the firms employed less than 50 people, $16 \%$ of the firms employed between 50 and 100 people, $22 \%$ of the firms employed between 100 and 500 employees, and the remaining $10 \%$ belong to large firms which employed more than 500 people. With regard to the position of the respondents, quality managers accounted for the largest proportion (39\%), followed by production/operations managers (18\%), directors, CEOs or general managers (16\%), and managers from other areas (13\%). 9\% of the respondents were quality control/system administrators. Only $5 \%$ of the respondents did not identify their managerial positions in the firms. Within our sample, firms have been certified with ISO 9001 , on average, for nine years.

\section{Measures}

The correlations and descriptive statistics of the variables used for this study are presented in Table II. In developing the measures, we have sought to derive the content from past studies on ISO 9000 to ensure their validity. Prior to the survey mail out, the questionnaire was sent to the representatives of JAS-ANZ for their feedback, particularly concerning the clarity of the content and the length of the questionnaire. In general, no specific concerns have been raised regarding the survey.

1) Intemalization of ISO 9000: For the internalization process of ISO 9000 standards, we have adopted the measures used in past studies [9], [14], [56]. It is deemed necessary here to emphasize that the internalization process captures the overall processes and stages of implementing ISO 9000 as quality management system, including installation and, maintenance, and internal audits of the standard.

2) Organizational Capital: The measure of organizational capital in the context of ISO 9000 is based on the concept of knowledge conversion [57]. Specifically, we have focused on two types of conversions: the externalization and the internalization processes of tacit and codified knowledge [10]. First, ISO 9000 requires firms to document their critical processes which affect the quality of products or services [22]. In this regard, ISO 9000 formalizes a codification process of tacit knowledge, which is embedded in the employees, into codified knowledge in the form of written document of the quality manual and operating procedures (clause 4.1. and 4.2.1). This process is called the externalization of tacit knowledge [57]. Second, ISO 9000 also requires that once these standard operating procedures are established, employees need to adhere to the prescribed practices in performing their tasks [22].

3) Human Capital: In measuring human capital in the context of ISO 9000, we focused on two major themes: competence and motivation. The importance of these two aspects has been well noted in the literature on human resources management [58]. ISO 9000 requires firms to establish schemes and procedures for training their employees (clause 6.2.2) with the purpose of ensuring their competence (clause 6.2.1); that is the ability to perform their assigned work and to meet standards that apply in the particular job. ISO 9000 also requires firms to maintain work environment needed to achieve high quality outputs of the works (clause 6.4). The work environment includes botl physical and psychological factors that can affect the emotions and attitudes of people, and therefore, the motivation of people toward the job to which they have been assigned [22]. 


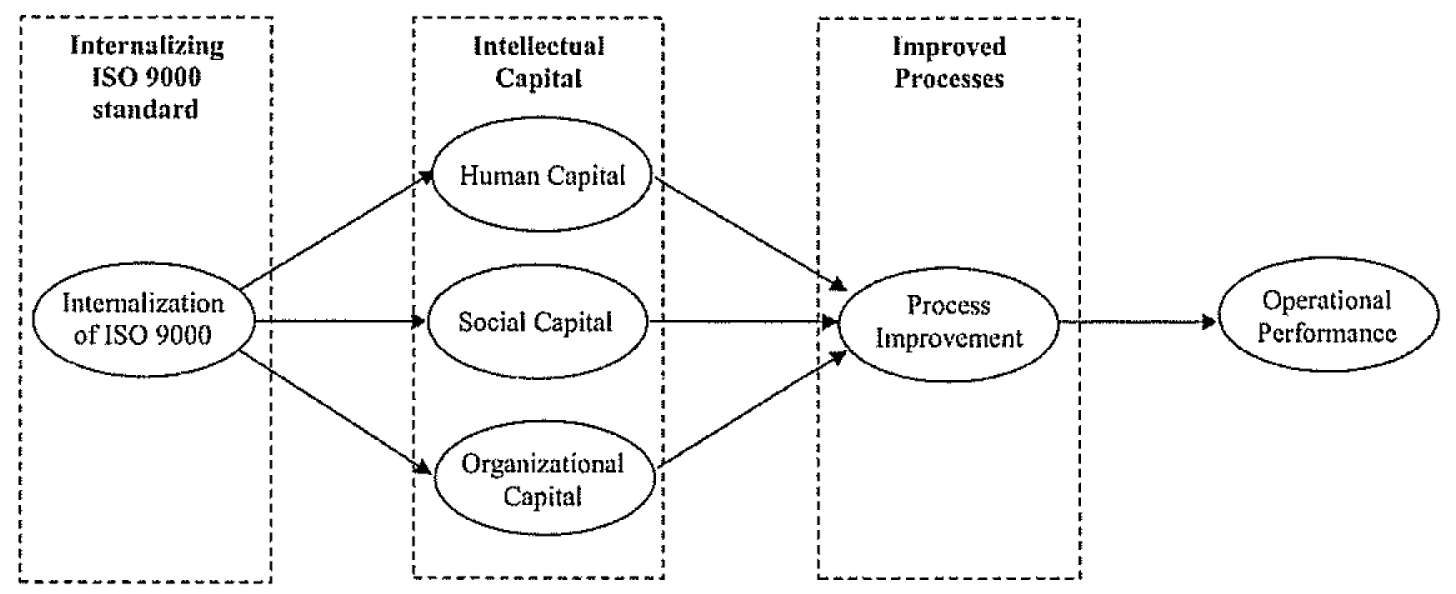

Control Variables: Organizational sizc, year of certification, organizational age, and organizational revenue

Fig. 1. Conceptual model.

TABLE 1

INDUSTRY SECTORS

\begin{tabular}{|c|c|c|c|}
\hline Industry seetors & $\%$ or sample & & \\
\hline Food, Beverage \& Tobacco & 6.4 & Construction & 7.4 \\
\hline Textile, Clotling, Footwear \& Leather & 4.6 & Other non-manufacturing & 28,2 \\
\hline Wood \& Paper Product & 1.8 & Health Care & 8.3 \\
\hline Printing, Publishing \& Recorded Media & 2.8 & Education and Training & 1,8 \\
\hline Petroleum, Coal, Chemical \& Associated Product & 1.8 & Government & 1.2 \\
\hline Non-Metallic Mineral Product & 9.8 & Trate/Construction & 5,2 \\
\hline Metal Prodttet & 1.5 & Environment & 3.4 \\
\hline Machinery \& Equipment & 6.4 & Prolessional Services & 1.5 \\
\hline Other manufacturing & 5.5 & Not Specified & 2.4 \\
\hline
\end{tabular}

TABLE II

CORRELATIONS AND DESCRIPTIVE STATISTICS

\begin{tabular}{|c|c|c|c|c|c|c|c|c|c|c|c|c|c|}
\hline & & Mean & Std. Dev. & $v_{1}$ & $\mathrm{v} 2$ & $\sqrt{3}$ & $V_{4}$ & v5 & V6 & $V_{7}$ & v8 & vg & V10 \\
\hline Organizational size & v1 & 1.95 & 1.17 & 1.00 & & & & & & & & & \\
\hline Organizational revenue & $\sqrt{ } 2$ & 2.48 & 0.87 & $0.64^{*}$ & 1.00 & & & & & & & & \\
\hline Organizational age & v3 & 31.71 & 28.39 & $0.32^{*}$ & $0.21^{*}$ & 1.00 & & & & & & & \\
\hline Year of certification & $V_{4}$ & 1998.51 & 4,30 & $-0.20^{\circ \prime}$ & $-0.28^{*}$ & $-0.27^{*}$ & 1.00 & & & & & & \\
\hline internalization & vs & 4.01 & 0.71 & -0.09 & $\cdot 0.07$ & -0.05 & .0 .01 & 1.00 & & & & & \\
\hline Kuman capita! & $v_{6}$ & 3.35 & 0.84 & 0.01 & -0.06 & 0.06 & $\cdot 0.04$ & $0.51^{*}$ & 1.00 & & & & \\
\hline Organizational captial & $\mathrm{V7}$ & 3.52 & 0.82 & 0.1 & 0.01 & 0.07 & .0 .05 & $0.38 "$ & $0.75^{-1}$ & 1.00 & & & \\
\hline Social capital & v8 & 3.21 & 0.87 & 0.08 & 0.03 & 0.02 & -0.09 & $0.39^{* \prime}$ & $0.66^{* *}$ & $0.69^{*}$ & 1.00 & & \\
\hline Process improvement & vg & 3.95 & 0.76 & 0.02 & -0.06 & .0 .01 & -0.06 & $0.44^{*}$ & $0.71^{*}$ & $0.72^{*}$ & $0.61^{\circ}$ & 1.00 & \\
\hline $\begin{array}{l}\text { Operational } \\
\text { performance }\end{array}$ & v10 & 3.66 & 0.73 & -0.03 & $0.14^{*}$ & -0.11 & 0.00 & $0.21^{*}$ & $0.21^{\prime *}$ & $0.23^{*}$ & $0.28^{\prime \prime}$ & $0.27^{* *}$ & 1.00 \\
\hline
\end{tabular}

4) Social Capital: To measure social capital, we adopt the concept suggested by Subramaniam and Youndt [12] that involves both intraorganizational and interorganizational relationslips. We include one item which represents the internal networks within the organization, namely continuous improvement culture; as continuous improvement is a mechanism, which facilitates the learning process between organizational members. Through various problem solving activities, members of the or- ganization will improve their knowledge and skills by sharing and exchanging their knowledge each other. For interorganizational social capital, we include items, which represent the relationship between the firm and their direct supply chain partners, specifically customers and suppliers.

5) Process Improvement: The main objective of process improvement is to ensure that the processes have consistency (minimum variation) and quality (conformance to specifications) in 
producing high quality products or services [23], [24], [59]. As such, ISO 9000 requires firms to develop and maintain production processes, which demonstrate consistency (clause 7.1) and conformance to the products' specifications (clause 8.1). In the pursuit of these goals, firms need to establish the monitoring, measurement, and analysis of the processes (clauses 4.le and 8.2.3). In addition, the 2000 version of ISO 9001 has required firms to demonstrate continuous improvement mechanisms in their processes (clause 4.1f). This new requirement drives firms to move away from solely focusing on conformance, but will encourage them to keep improving their processes [38]. We capture these main principles with the measures used in the questionnaire.

6) Operational Perfornance: In investigating the impact of ISO 9000 adoption, this study focuses on the operational level as highlighted in previous studies, e.g., [60]. As mentioned previously, the main purpose of the ISO 9000 standards is to provide guidelines for firms in building sound quality management system to produce products or services that meet customers' needs and expectations [22]. Therefore, the effect of the implementation process of this standard would be instantly seen at the operational level [61]. Several previous studies, while showing the eventual effect of ISO 9000 on business (i.e., financial) performance, have concluded that such an effect is mainly mediated by the operational performance [9]. The operational performance measure captures the elements that go beyond conformance to specifications. While ISO 9000 primarily aims to achieve high quality outcomes in terms of conformance to specifications, the effect of quality by conformance will positively affect outer aspects of the operational performance, including improved productivity [62], and reduced operating costs [25]. This study included three elements of operational performance, namely product performance, on time delivery, and cost effectiveness [4].

7) Control Variables: We included organizational size, age, revenue, and year of certification as the control variables in the model. There are various studies in the literature that consider organizational size and length of accreditation (measured by year of certification) as important factors, which should not be overlooked in the quality context [6], [53], [54]. Organizational structures vary with the size, since the hierarchical levels in the firm is directly related to number of employees. This impacts the information flow, which is an important factor regarding dissemination of ISO 9000 in the organization. We control the organizational size by incorporating the number of employees in the model. Furthermore, the duration of ISO 9000 is associated with the degree of change in the infrastructure of the organization. The diffusion of the quality system is expected to be stronger when ISO 9000 has been in place for a longer time period. Also, the age of the company is expected to influence the culture of an organization, hence, we control for it as well. The norms and customs influencing existing processes would be more deeply embedded in older organizations and it would be difficult to alter them due to resistance to change. We also included revenue as a control variable as larger and resourceful firms would likely exhibit higher levels of performance.
A five-point Likert scale was used for construct measurement. For internalization of ISO 9000 , human capital, organizational capital, social capital, and process improvement, the scales ranged from 1 (strongly disagree) to 5 (strongly agree). For the operational performance, the respondents were asked to assess their firm's relative performance against the major competitors in their industry with scales ranging from 1 (weakest in the industry) to 5 (strongest in the industry). The content of the five scales used in this study is presented in Table III.

\section{RESULTS}

\section{A. Scale Validity and Reliability}

As a first step, all constructs used in this study were subjected to validity and reliability tests. Confirmatory factor analysis was used to validate the measures of internalization of ISO 9000 standard, human capital, organizational capital, social capital, process improvement, and operational performance. The overall model fit results as reflected by the fit indices $\left(\chi^{2}=379.34\right.$; d.f. $=211$; root mean square enor of approximation (RMSEA) $=0.05$; normed fit index $(\mathrm{NFI})=0.97$; comparative fit index $(\mathrm{CFI})=0.98$; goodness of fit index $(\mathrm{GFI})=0.91)$ suggest unidimensionality of the constructs and the loading path of each item (which exceeds 0.50 ) supports the convergent validity for the measures [63], [64]. The Cronbach's alpha of the six scales exceeded the cutoff point of 0.7 , thus supporting their reliability [65]. The results of the confirmatory factor analysis and the Cronbach's alpha are presented in Table III.

Since the responses were collected from a single respondent in the organization, common method variance was checked to ensure that the data had no major problem related to responsebias. We used Harman's single-factor test as suggested by Podsakoff and Organ by loading all items into one common latent variable [66]. The result of this measurement model showed an extremely inflated Chi-square value $\left(\chi^{2}=1146.22\right.$; d.f. $\left.=226\right)$ and poor fit indices with many items suffered from poor path loadings $(<0.4)$ to the latent variable. We therefore concluded that common method variance was not a substantive problem in our data.

Finally, we conducted discriminant validity analysis to check if all constructs used in this study are distinct from each other. We followed the method suggested by Venkatraman by checking discriminant validity between two constructs in pairs [70]. For each pair, confirmatory factor analysis (CFA) was conducted twice. The first CFA allowed the correlation between the two constructs to be freely estimated while in the second CFA, the correlation between the two constructs was fixed to 1.0. The difference between the Chi-squares values of the first and second CFA (i.e., $\Delta \chi^{2}$ ) was compared. If the $\Delta \chi^{2}$ value is greater than 6.64 , the two constructs are statistically distinct at $p<$ 0.01 , thereby providing a reasonable evidence of discriminant validity [59]. With six constructs incorporated in this study, we conducted 15 Clii-square tests. The values of $\Delta \chi^{2}$ (presented in Table IV) for all tests passed the cutoff point, confirming the discriminant validity of the constructs and lend further evidence toward the nonexistence of common method variance. 
TABLE III

CONFIRMATORY FACTOR ANALYSIS

\begin{tabular}{|c|c|c|c|}
\hline Scales & Items & $\begin{array}{l}\text { Londing } \\
\text { paths }\end{array}$ & $\begin{array}{c}\text { Cronbach's } \\
\text { alpha }\end{array}$ \\
\hline \multirow[t]{6}{*}{$\begin{array}{l}\text { Internalization } \\
\text { of ISO } 9000\end{array}$} & $\begin{array}{l}\text { All employees were trained in total quality concepts and ISO } 9000 \\
\text { requirements during the implementation process }\end{array}$ & 0.59 & 0.82 \\
\hline & $\begin{array}{l}\text { Our company's quality policy, objectives, and procedures were } \\
\text { explained clearly to all employees }\end{array}$ & 0.57 & \\
\hline & $\begin{array}{l}\text { We clearly documented the quality policy and procedures for } \\
\text { quality management and continuousty update them }\end{array}$ & 0.68 & \\
\hline & We always maintain our daily practices to comply with the & & \\
\hline & documented procedures based on the ISO 9000 requirements & 0.76 & \\
\hline & $\begin{array}{l}\text { We conduct internal audit regularly and the results are used as a } \\
\text { basis for improving our processes }\end{array}$ & 0.73 & \\
\hline \multirow[t]{5}{*}{ Human Capital } & Enhanced employee skills and competencies & 0.77 & 0.87 \\
\hline & Improved employees morale and motivation in performing their & & \\
\hline & tasks & 0.78 & \\
\hline & Improved foundation for training and education & 0.80 & \\
\hline & Enhanced confidence and effectiveness in performing tasks & 0.79 & \\
\hline Organizational & Improved documentation of the knowledge of all critical processes & 0.71 & 0.86 \\
\hline \multirow[t]{3}{*}{ Capital } & Improved storage and retrieval of new knowledge and information & 0.72 & \\
\hline & Entianced the use of information to improve products and processes & 0.85 & \\
\hline & Enhanced knowledge dissemination in the organisation & 0.83 & \\
\hline \multirow[t]{3}{*}{ Social Capital } & Enhancing the understanding of customer needs & 0.72 & 0.75 \\
\hline & Improving information sharing with suppliers & 0.59 & \\
\hline & Enhancing continuous learning and improvement culture & 0.78 & \\
\hline Process & Enhanced the consistency of the way processes are performed & 0.79 & 0.86 \\
\hline \multirow[t]{3}{*}{ Improvement } & Established a sound measurement and control system of processes & 0.78 & \\
\hline & Established corrective and improvement mechanism of processes & 0.77 & \\
\hline & Improved process capability in conforming to specifications & 0.73 & \\
\hline & Product performance & 0.68 & 0.74 \\
\hline \multirow[t]{2}{*}{ performance } & On time delivery & 0.65 & \\
\hline & Cost effectiveness & 0.77 & \\
\hline & $25 \mathrm{NF}$ & & \\
\hline
\end{tabular}

TABLEIV

DISCRIMINANT VALIDITY

\begin{tabular}{llcccccc}
\hline & & C1 & C2 & C3 & C4 & C5 & C6 \\
\hline Internalization of ISO 9000 & (C1) & - & 227.08 & 297.77 & 232.12 & 254.37 & 381.40 \\
Human Capital & (C2) & & - & 163.76 & 49.23 & 62.97 & 374.31 \\
Organizational Capital & (C3) & & & - & 57.86 & 85.02 & 369.91 \\
Social Capital & (C4) & & & & - & 76.19 & 317.33 \\
Process Improvement & (C5) & & & & & - & 360.36 \\
Operational Performancc & (C6) & & & & & & \\
\hline
\end{tabular}

\section{B. Structural Model}

We present the results of the structural equation model in Fig. 2. Four control variables (organizational size, age, revenue, and year of certification) were applied to the endogenous variable (operational performance). Overall, the model shows a good fit. The fit indices (NFI $=0.96, \mathrm{CFI}=0.98, \mathrm{GFI}=0.90$ ) and error index (RMSEA $=0.04$ ) indicate that the model fit is good. The ratio of $\chi^{2}$ (496.05) to degrees of freedom (300) is well below the recommended cutoff point of 3.0 for satisfactory fit of a model to data [63], [67]. The results of the hypotheses are outlined in Fig. 2.

First, the internalization of ISO 9000 standards is significantly related to human capital $(0.64$ at $p<0.01)$, organizational capital $(0.45$ at $p<0.01)$, and social capital $(0.55$ at $p<0.01)$; therefore, $\mathrm{H} 1 \mathrm{H} 2$, and $\mathrm{H} 3$ are supported. Both human capital and organizational capital are significantly related to process improvement $(0.58$ at $p<0.01$ and 0.28 at $p<0.05$ respectively); thus, supporting $\mathrm{H} 4$ and $\mathrm{H} 5$. It is noted that the effect. from human capital is relatively higher than that of from organizational capital. Social capital, however, does not have a direct positive relationship with process improvement. Thus, $\mathrm{H} 6$ is not supported. Finally, process improvement is significantly related to operational performance $(0.35$ at $p<0.01)$; hence, supporting $\mathrm{H} 7$. In addition, the model also estimates the error correlations $(\psi)$ among the three intellectual capital elements to test the exclusive correlations among them over and above the variance explained by their common antecedent (i.e., internalization). The results show that human capital is significantly correlated with both organizational capital $(0.48$ at $p<0.01)$ and social capital $(0.50$ at $p<0.01)$. while social capital is 


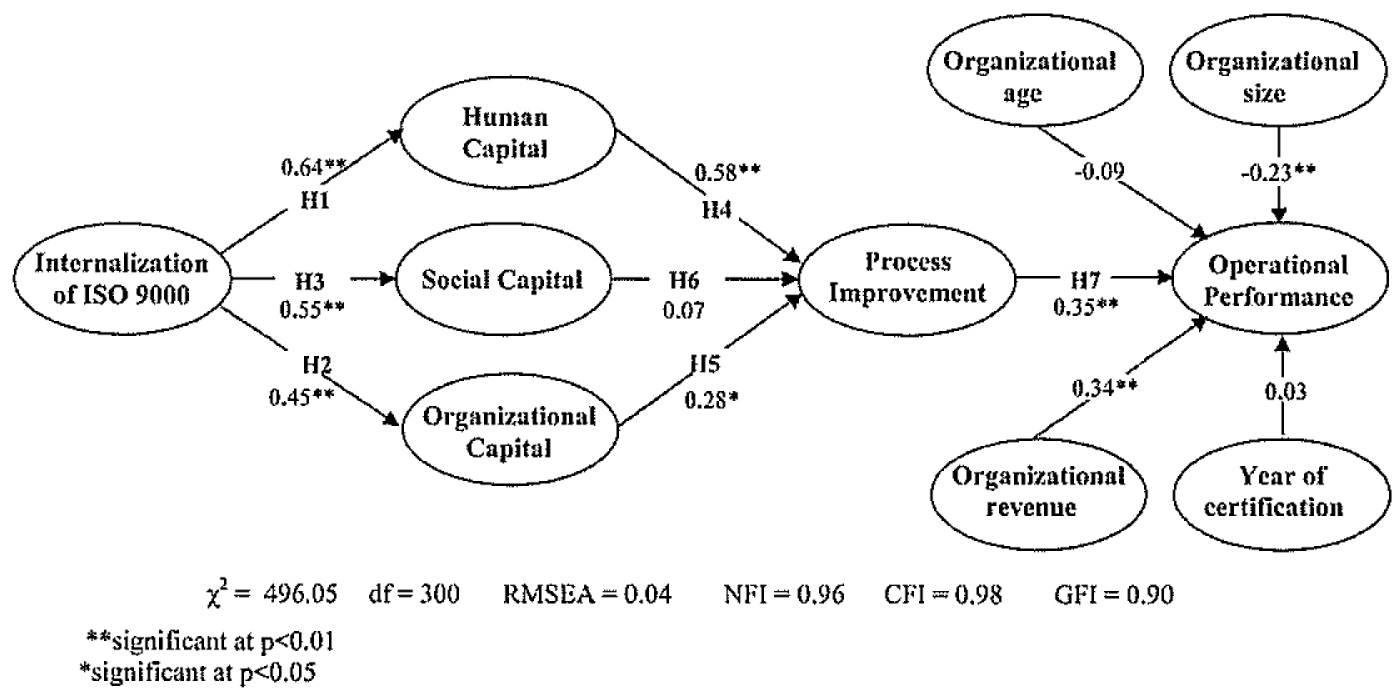

Fig. 2. Path diagram.

also significantly correlated with organizational capital $(0.63$ at $p<0.01$ ).

For a confirmatory purpose, a competing model is tested by adding five additional paths: internalization-process improvement, internalization-operational performance, organizational capital-performance, human capital-performance, and social capital-performance. None of these additional paths was significant, and indeed, the overall fit of the model was getting poorer. This lends further support toward the validity of the tested model and the appropriateness of the conceptual framework.

\section{DISCUSSION OF THE FINDINGS AND IMPLICATIONS OF THE STUDY}

\section{A. Theoretical Implications}

The framework proposed in this study brings internalization of ISO 9000 standards, knowledge management, and human resources management together to explain the dynamics of successfully managed processes. The fit of the overall structural model implies that the data aligns well with the hypothesized model. Significant paths from internalization of ISO 9000 to human capital, organizational capital, and social capital show that internalization of ISO 9000 impacts all dimensions of intellectual capital, which in turn collectively trigger commitment of the employees to a common understanding as to how the tasks are performed as well as shape the overall direction of the organization.

The theoretical lens of resource-based view explains our model well, since the tenets of intellectual capital emerge as a result of internalization of ISO 9000 and the transformation of human and knowledge resources into firm assets/capitals drive superior performance and sustainable competitive advantage. The activities related to internalization, such as training, clear documentation, adherence to practices, and procedures guided by ISO 9000 standards on a daily basis impact the procedures and systems that are not only at the functional level but also the ones that are organization-wide. The internalized ways and procedures provide the foundation for organizational capital by setting clear guidelines for organizational routines. Internalized procedures shape, guide, and direct the behavior of the employees regarding organizational tasks, which help in forming human capital manifested in terms of skilled, motivated, and self-confident employees. Additionally, by emphasizing relationships among internal and external constituents engaged in business processes, internalization of ISO 9000 standards help in fostering social capital.

Human capital, manifested in terms of skilled and wellinformed labor force, helps in identifying means to improve existing processes. The employees commit to the general understanding of the accomplishment of tasks and circulation of knowledge and know-how throughout the organization, and apply themselves accordingly. Eventually, the operational processes are performed consistently and with high quality. The operational performance is then impacted positively. The organization gains resources that stem from a functional improvement program and turns it into valuable assets that improve the organization at large in ways that impact its structure. Likewise, organizational capital, in the form of enhanced ways of storage, retrieval, and dissemination of knowledge throughout the organization, provides the basis of a knowledge reference repository regarding activities. Those resources get embedded in the organization and provide the basis for process improvement and operational performance.

Contrary to the expectations, the link between social capital and process improvement was not supported by our empirical data. Perhaps, it is conceivable that social capital with its emphasis on relationships might be playing a somewhat different role than that of human and organizational capital. Since social capital acts as a facilitator that strengthens the leverage gained by human and organizational capitals [12], it could potentially be mediating or moderating the relationships between the other two dimensions of intellectual capital and process improvement. Additional research is needed to gain insights into the role of social capital. 
The results of this study indicate that in order to gain performance benefits from ISO 9000 standards, organizations should intemalize these standards and create a commitment in the organization by close connection and interplay between the elements of intellectual capital. The synergies between the dimensions of intellectual capital are formed when ISO 9000 standards are adopted not solely for "certification" purposes but as a fully dedicated improvement program. The synergistic adoption of various dimensions of intellectual capital leads to structural changes that would not be possible if ISO standards are not fully internalized in the organization. Thus, achieving functional benefits of the improvement program is only possible with a continual effort to comply with the main principles of ISO 9000 in human resource and knowledge management areas, rather than considering the ISO 9000 certificate as the final destination in quality context.

From the intellectual capital perspective, this study demonstrates the substantial effect of intellectual capital in building capabilities for achieving process improvement and higher operational performance. As such, this study extends the application of the intellectual capital theory in the context of quality management system, particularly in process improvement. As noted earlier, the 2000 version of ISO 9000 has put a greater emphasis on improvement rather than merely compliance. Our results indicate that process improvement and consequent operational performance relies on certain level of intellectual capital.

\section{B. Managerial Implications}

There are also several managerial implications resulting from our study. We show how continuous improvement initiatives in the ISO 9000 internalization process result in enhanced use of information to improve products and processes as well as in development of human capital. Internalization of ISO 9000 initiates training and development programs for the workforce, and documentation and storage requirements for the knowledge dissemination throughout the organization. As a result, the organization becomes a medium of proficient knowledge sharing and socialization of the competent employees. These factors enable the firm to move toward superior performance. This indicates that managers should focus on internalization of ISO standards instead of merely aiming for ISO 9000 certification. This helps in boosting confidence of employees and enhancing their effectiveness in performing tasks. It also results in more consistency in terms of the way various activities are performed within an organization.

Knowledge management practices resulting from internalization of ISO 9000 standards create norms and procedures as to how the knowledge is stored and disseminated in the organization. The employees refer to the codebooks, which are basically the stored knowledge, and rely on each other to achieve process improvement. Effective development of organizational and human resource capabilities with the help of internalized ISO 9000 standards enable an organization to outcompete other firms. This study shows that the implementation of ISO 9000 is not simply about complying with the requirements and attaining the certification; rather, it is concerned with the intel- lectual structure of the firm. Understanding this issue represents a real step forward in developing capabilities since the focus is now on the effectiveness of the quality system for the entire organization as against solely the "conformance" of processes to the prescriptions of ISO 9000 standards. A quality management system, such as ISO 9000 standards, must be focused on internalizing knowledge about processes and the steps needed for process improvement as against merely on compliance to set procedures [68]. Therefore, while ISO 9000 certification does not provide competitive value on its own due to its imitability, the internalization process provides a good platform for intellectual capital building, if managed properly.

In conjunction with the aforementioned point, the findings of the study point to the need for balancing knowledge with competent workforce within the quality management system as both human resources and knowledge storage devices, routines and emergent network structures are potential assets for organizations. Given the differences in their nature, each of these types of assets will require unique kinds of investments [69]. The findings of this study emphasize the importance of building complementarties mainly between organizational capital and human capital, which will together produce more effective and unique capabilities for organizations.

\section{CONCLUSION, LiMITATIONS, AND DiRECTIONS FOR FUTURE RESEARCH}

Knowledge embedied in organizations can be the source of sustained competitive advantage. Quality management and the importance of knowledge management in internalization of ISO 9000 standards in particular, are no exceptions. We proposed that intellectual capital, emerged through the internalization of ISO 9000 standards, acts as the underlying mechanism that enhances the process management in the organization. Consequently, improved processes ensue, and they result in higher operational performance. This study contributes to the literature as it empirically validates this theoretical framework. Drawing on the resource-based view and the framework of intellectual capital, we show that internalization of ISO 9000 influences intellectual capital, which in turn impact process improvement and operational performance.

Since no study is free from limitations, we would like to point to some of the limitations of this study and offer directions for future investigations. First, while objective performance measures would be ideal, we resort to the perceptual measures given the constraints of obtaining objective performance measures in large-scale surveys. An examination of the conceptual framework considered in this study with objective performance measures would further enhance our understanding of the underlying phenomenon. Second, although it would be ideal to have multiple respondents to have inter-rater reliability as to the responses, large number of participant firms make it difficult to collect data from more than one respondent per firm. Therefore, we had to resort to single respondent per organization. We acknowledge this limitation and suggest a multiple respondent study as a future research opportunity. 
Finally, the results of this study fail to find the role of social capital on process improvement. Perhaps, social capital might have taken on an important part if we were to consider business performance and supply chain performance. The network spanning role as well as the facilitating role of social capital would likely play a key role in these performance contexts. Alternatively, social capital may be acting as a moderator or a mediator, rather than having a direct effect on process improvement. Future studies can investigate the role played by social capital in linking internalization of ISO 9000 standards to performance.

\section{REFERENCES}

[1] K. Lai and T. C. E. Cheng. "Initiatives and outcomes of quality manngement implementation across industries," Omega, vol. 31. pp. 141-154, 2003.

[2] K. R. Bettie and A.S. Sohal, "Implementing ISO 9000: A study of its benefts anong Australián organizations," Total Quality Manage., vol. 10, pp. $95-[06,1099$.

[3] M. Casadesus, G. Gimenez, and I. Heras, "Benefits of ISO $9000 \mathrm{im-}$ plementation in Spanisla industry," Eur: Bus. Rey, vol. 13, jp. 327-335, 2001.

[4] E. Naveh and A. Marcus, "When does the ISO 9000 quality assurance standard lead to performance improvement? Assimilation and going beyond," IEEE Trans. Eng. Manage, vol. 51, no. 3, pp. 352-363, Aug. 2004.

[5] K. D. Gotzamant and G. D. Tsiotras, "The true motives behind ISO 9000 certification: their effect on the overall certification benefits and long term contribution towards TQM," Int. J. Quality Rel. Manase, vol. 19, pp. $151-169,2002$.

[6] M. Abraham, J. Crawtord, D. Carter, and F. Mazota, "Management decisions for effective ISO 9000 acereditation," Manage Decision. vol. 38, pp. 182-193, 2000.

[7] $\mathrm{M}$ J Benner and F. M. Veloso, "ISO 9000 practices and financial performance: A technology coherence perspective," J. Oper: Matutge. vol. 26, pp. $611-629,2000$.

[8] J. B. Bantney, "Strategic factor markets: Expectations, luck and business strategy." Mantige. Sci., vol. 32, pp. 1231-1241.1986.

[9] E. Navelı and A. Marcus, "Achieving competitive advantage through implementing a replicable management standard: installing and using iSO $9000, *$, Opes: Manage., yol. 24, pp. 1-26, 2005.

[10] D. Benezecl, G. Lambert, B. Lanoux, C. Lerch, and J. Loos-Baroin, "Completion of knowledge codification: an illustration through the ISO 9000 standards implementation process," Res. Policy, vol. 30, pp. 1395-1407. 2001.

[11] C. Lin and C. Wu, "Managing knowledge contributed by ISO $9001: 2000$," Int. J. Quality Rel. Manages, vol. 22. pp. 968-985, 2005.

[12] M. Subramariam and M. A. Yound. "The influence of intellectual capital on the types of innovative capabilities," Academy Marage. J., vol. 48, pp. 450-463, 2005 .

[13] J. B. Barney, "Firm resources and sustained competitive advantage," $J$. Manage, vol. 17, pp, 99-120. 1991.

[14] J. A. Briscoe, S. E. Fawcet, and R. H. Todd, "The implementation and impact of ISO 9000 arnong small manufacturing enterprises," J. Small Business Manage., vol. 43, pp. 309-330, 2005.

[15] A. Nair and D. Prajogo, "Internalization of ISO 9000 standards: the antecedent role of functionalist and institutionalist drivers and performance implications," Im. J. Prod. Res., vol. 47, pp. 4545-4568, 2009.

[16] M. Y. Ismail and M. S. Haslmi, "The state of quality management in the Itish manufacturing industry," Tonal Quratity Manage.. vol. 10. pp. 853$862,1999$.

[17] F. Huamg, C. Horng, and C. Chen, "A study of iSO 9000 process, motivation and performance," Total Quality Wanage., vol. 10, pp. 1009m1025, [999.

[18] K.S. Lee and E Palmer, "An empirical examination of ISO 9000registered companies in New Zcaland," Total Qutality Manage, vol. 10, pp. 887-899, 1999

[19] I. Nonaka, "A dynamic theory of organisational knowledge creation," Org. Sci., vol. S, pp. 14-37. 1994.

[20] M. T. Hansen, N. Nohria, and T. Tierney, "What's your strategy for managing knowledge?" Hanard Business Rev, pp. 106-116, Mar./Apr. 1999.
[21] S. A. Snell and J.W. Dean Jr., "Integtated miniufacturing and hurnan resource management: A human capital perspective," Acalemy Manage. J., vol. 35. pp. 467-504, 1992.

[22] D. Hoyle, ISO 9000 quality systems handbook-ISO 9000:2000 version, 4th ed. Oxford, U.K.: Butterworth-Heinemann, 2000.

[23] C. J. Corbett, M. J. Montes-Sancho, and D. A. Kirsch, "The financial impact of ISO 9000 certification: An empirical analysis," Manage. Sci. vol. 51, pp. 1046-1059, 2005.

[24] W. E. Deming, Out of the Crisis; Centre for Advanced Engineering Sindy. Cambridge, MA, USA: Massaclusetts Institute of Technology, 1986.

[25] J. M. Juran and F. M. Gryna, Qtatlity Planning and Anolysis. 3 rd ed. New York, NY, USA: McGraw Hill, 1993.

[26] J. Jayaram, C. Dioge, and S. K. Vickery, "The impact of human resource manigenent practices on manufacturing performance," J. Oper Manage. vol. I8, pp. 1-20, 1999.

[27] J. P. MacDulfie and T. A. Kochan, "Do U.S. firms invest less in human resources? Training in the world auto industry," Ind. Relatons, vol. 34, pp. 147-68, 1995.

[28] T. Hughes, T. Williams, and P. Ryall, "It is not what you achieve it is the way yot achieve it," Total Quality Manage, vol. 11, pp. 329-340. 2000.

[29] S. Karapetrovic and W. Willborn, "ISO 9000 quality management standards and financial investment services," Service Itth. $J$, vol. 21, pp. 117 $136,2001$.

[30] L. Argote and P. Ingram, "Knowledge transfer: A basis for competilive advantage in firms," Orgemizational Beharior Human Decision Process. vol. 82, pp. 150-169, 2000.

[31] M. A. Peteraf, "The cornerstones of competitive advantage: A resourcebased view." Strategic Manage. J., vol. 14, pp. 179-191, 1993.

[32] D. S. Docking and R. J. Dowen. "Market interpretation of iSO 9000," $J$. Financial Res., vol. 22, pp. 147-160, 1999.

[33] E. Bendoly, A. Citurs, and B. Konsynski, "Internal infrastructural impacts on RFID perceptions and commitment: Knowledge, operational procedures and information-processing standards," Decision Sci., vol. 38. pp. 423,449, 2007

[34] M. Granovetter, "Economic institutions as social constructions: A framework tor analysis," Acta Sociologica, vol, 35, pp. 3-1 1, 1992.

[35] J. S. Coleman, "Social capital in the creation of human capital," Amer. $J$. Sociol, vol. 94, pp. 95-120. 1988.

[36] G. A. Knight and P. W. Liesch, "Information internalisation in internationalising the firm," J. Bus. Res., vol. 55, pp. 981-995, 2002.

[37] S. W. Anderson. J. D. Daly, and M. F. Johnson, "Why firms setk ISO 9000 certification: Regulatory compliance or competitive advantage?" Prod. Opes: Mantige, vol. 8, pp. 28-43, 1999.

[38] M. Imai, Kaizen: The Key to Japan's Competitive Success. New York, NY. USA: Random House, 1986.

[39] J. Roos and D. Oliver, The Poised Organization: Navigating Effectively on Knowledge Londscape. Thousand Oaks, CA, USA: Sage, 1999.

[40] T. Davenport, H. Thomas, and L. Prusak, Working Knowledge: How Orgatnizations Manage What The; Know. Boston, MA, USA: Harward Business School Press, 2000.

[4I] S. Shoham and A. Hasgall, "Knowleclge workers as fiactals in complex adaptive organizations," Knowl. Process Manage, vol. 12, pp. 225-236, 2005.

[42] A. Hasgail and S. Shoham, "Knowledge processes-From managing people to managing processes," J, Knowl. Monage., vol. 12, pp. 51-62, 2008.

[43] K. Dooleby, Organizational complexity; in Warner, M. (Ed.). International Encyclopedia of Business and Managenent. London. U.K.: M. Thompson Leiltring, 2002, pp. 5013-5022.

[44] H. Bajaria, "Approaching quality in an ever-changing world," Total Quality Mtonage, vol. 12. pp. 842-848, 2001.

[45] I. Nonaka, R. Toyama, and A. Nagala, "A firm as a knowledge creating activity: A new perspective on the theory of the firm," Ind. Corporate Change, vol. 9, pp. 1-20. 2000.

[46] A. S. Bollinger and R. D. Smith, "Maniging organizational knowledge as a strategic asset," J. Knowl. Manage., vol. 5, pp. 8*18, 2001.

[47] C. Sheldon, ISO I400I and Beyond: Envirommental Mandgement Systents in the Real World. New York, NY, USA: Prentice Hall, 1997.

[48] D. J. Teece and G. Pisano, "The dynamic capabilities of firms: An introduction," Ind. Corporate Change. vol. 3, pp. 537-556, 1994.

[49] A.Zuckerman, "Some believe QS-9000 plays no role in situation," Quality Progr., vol. 33, pp. 45-46, 2000.

[50] K. N. Dervitsiotis, "Quality in Greece: Past and present." TQM Mag., vol. 11, pp. 84-87. 1999.

[51] D. J. Teece, G. Pistno, and A. Sluen, "Dynamic capabilities and strategic management," Strategic Mentage. J, vol. 18, pp. 509-533, 1997. 
[52] K. M. Eisenhardt and J. A. Martin, "Dynamic capabilities: What are they?" Strategic Matuage. J., vol. 21, pp. 1105-1121, 2000.

[53] M. Terziovski, D. Samson, and D. Dow, "The business value of quality management systems certification: Evidence from Ausitalia and New Zealand," J. Oper: Mamage, vol. 15, pp. 1-18, 1997.

[54] J. Jayaram, S. L. Ahire, and P. Dreyfus, "Contingency relationships of firm size, TQM duration, unionization, and industry context on TQM implementation-A focus on total effects," J. Oper Manage., vol. 28 , pp. $345-356,2010$.

[55] J. S. Armstrong and T. S. Overton, "Estimating nonresponse bias in mail surveys," I. Marketing Re.s, vol. 14, pp. 396-402, 1977.

[56] R. Aaruz and H. Suzuki, "ISO 9000 performance in Japanese industries." Total Quality Manage. Bus. Excellence, vol, 15, pp. 3-33.2004.

[57] I. Nonaka and H. Takeachi, The Knowledge-Creating Company. New York, NY, USA: Oxford Univ, Press, 1995.

[58] M. Subramony. "A meta-analytic investigation of the relationship between HRM bundles and fitm performnnce," Himon Resource Manage., vol. 48, pp. 745-768, 2009.

[59] S. L. Ahire, D. Y. Gollar, and M. A. Waller, "Development and validation of TQM implementation constructs," Decision Sci, vol. 27, pp. 23-56, 1996.

[60] L. Santos and C. Escanciano, "Benefits of the ISO 9000:1994 system: Some considerations to reinforce competitive advantage." Int. J. Quality Rel. Munctee, vol. 19, pp. 321-344. 2002.

[61] J. Motwani, A. Kumar, and C. H. Cheng. "A rondmap to implementing ISO 9000," Int. J. Quality Rel. Manage.. vol. 13, pp. 72 83, 1996.

[62] W. E. Deming, Quality, Productivity: and Competitive Position: Centre for Advanced Engineering Sudy. Cambridge, MA, USA: Massachusetts Institute of Technology, 1982

[63] K. A. Bollen, Stuttural Equations With Lasent Variables. New York, NY, USA: Wiley, 1989.

[64] R. P. Bagozzi, Y. Yi, and L. W. Philips, "Assessing construct validity in organizalional researcl," Administ. Sci. Quarterby, vol. 36, pp. 421-458, 1991.

[65] J. Nunnally, Psychometric Theory. New York, NY, USA: McGraw-Hill, 1978.

[66] P. M. Podsakoff and D. Organ, "Self-reports in organizational research," J. Manage, vol. 12, pp. 53 I-544, 1986.

[67] J. F. Hair, R. E. Anderson, R. L. Talkam, and W. C. Black, Mutrivariate Data Analysis. Upper Saddle River, NJ, USA: Prentice-Hall, 1998.

[68] T. Conti, "Quality standards developnent in a hypercompetitive scenario," TQM Mag., vol. 1I, pp. 402-408, 1999.

[69] M. A. Youndt, M. Subramaniam, and A. Snell, "Intellectnal capital profites: An examination of investments and returns," J. Manage. Studies, vol. 41, pp. 335-361, 2004.

[70] N. Vetkatranan, "Strategic orientation of business enterprises: the construct, dimensionality, and measurement," Matutage. Sci., vol. 35. pp. 942$962,1989$.

[71] L. Hvam, P. Nielsen, and O.C. Bjalno, "Re-engineering callued by ISO 9000 certification," Btes. Process Manage. J., vol. 3, no. 3, pp. 192-204. 1997.

[72] D. A. Garvin, "Competing on the eight dimensions of quality," Harvard Business Rev., pp. 101-109, Nov. 1987. 